\title{
Idiopathic small-bowel intussusception in an adult
}

\section{Pietro Renzulli MD, Daniel Candinas MD}

$\mathrm{A}$ previously healthy 30 -year-old woman presented with intense left-sided abdominal pain. Results of routine blood tests were normal. A computed tomography image was highly suggestive of small-bowel intussusception (Appendix 1, available at www.cmaj.ca /cgi/content/full/cmaj.090457/DC1). ${ }^{1}$ A diagnosis of jejunojejunal intussusception was confirmed by laparoscopy (Figure 1). Neither ischemia nor substantial inflammation were evident. A reduction of the intussusception was attempted laparoscopically but was not successful. A small infraumbilical laparotomy $(4 \mathrm{~cm})$ was then performed and allowed an easy manual reduction. A meticulous inspection by palpation and translumination of the patient's entire small bowel showed no underlying pathology (i.e., lead point) that may have triggered the intussusception. A bowel resection was therefore not performed. The postoperative course was uneventful and the patient remained free of symptoms during a three-year follow-up period.

Intussusceptions are the most common cause of intestinal obstruction in children between three months and six years of age. Most instances (more than 90\%) are idiopathic. Standard treatment is either nonsurgical pneumatic or hydrostatic reduction.

In adults, intussusception is exceedingly rare, representing less than $5 \%$ of all intestinal obstructions. In contrast to the pediatric population, about $90 \%$ of intussusceptions in adults are associated with a pathologic lesion, or lead point, in the bowel wall. Recent studies show that $30 \%$ of small-bowel intussusceptions are caused by malignancy. The remainder of instances are caused by benign lesions (60\%) or are idiopathic $(10 \%)$. Most colonic intussusceptions, however, are caused by malignancy $(60 \%) .^{2-5}$

The standard treatment of intussusception in adults is surgical, without prior nonoperative attempts at reduction. ${ }^{2}$ Because of the high incidence of malignancy, especially in colonic intussusceptions, a segmental bowel resection without prior intraoperative reduction is generally undertaken. ${ }^{2-4}$ How-

From the Department of Visceral Surgery and Medicine, Inselspital, Bern University Hospital, and the University of Bern, Bern, Switzerland

CMAJ 2009. DOI:10.1503/cmaj.090457

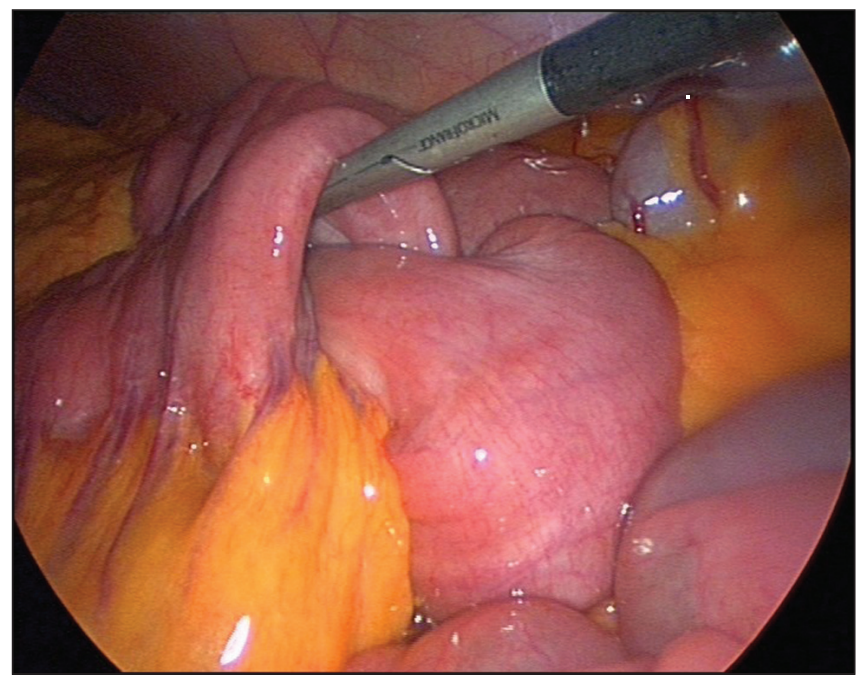

Figure 1: Laparoscopic image of the small bowel of a 30-yearold woman, showing a jejunojejunal intussusception.

ever, an alternative approach may be useful for patients with "pediatric-type" idiopathic small-bowel intussusception. ${ }^{3,4}$ In these patients, a surgical, preferably laparoscopic, exploration may be helpful. In the absence of inflammation or ischemia, a cautious attempt at surgical reduction may be justified., ${ }^{3,4}$ The finding of a healthy small bowel with no underlying pathology will prevent the need for a bowel resection.

This article has been peer reviewed.

Competing interests: None declared.

\section{REFERENCES}

1. Kim YH, Blake MA, Harisinghani MG, et al. Adult intestinal intussusception: CT appearances and identification of a causative lead point. Radiographics 2006;26:733-44

2. Barussaud M, Regenet N, Briennon X, et al. Clinical spectrum and surgical approach of adult intussusceptions: a multicentric study. Int J Colorectal Dis 2006;21:834-9.

3. Goh BKP, Quah HM, Chow PKH, et al. Predictive factors of malignancy in adults with intussusception. World J Surg 2006;30:1300-4.

4. Zubaidi A, Al-Saif F, Silverman R. Adult intussusception: a retrospective review Dis Colon Rectum 2006;49:1546-51.

5. Chiang JM, Lin YS. Tumor spectrum of adult intussusception. J Surg Oncol 2008;98:444-7. 